\title{
OCULAR DISORDERS ASSOCIATED WITH THE WISDOM TOOTH*
}

\author{
B Y
}

\author{
C. Bowdler Henry, L.R.C.P., M.R.C.S., L.D.S.(Eng.) \\ HUNTERIAN PROFESSOR, ROYAL COLLEGE OF SURGEONS OF ENGLAND \\ HON. DENTAL SURGEON AND LATE LECTURER IN ORAL \\ SURGERY, ROYAL DENTAL HOSPITAL, LONDON
}

Ir is nowadays a commonplace of ophthalmological practice that inflammatory conditions of the eye can often be traced back to septic foci in the mouth, and a dental examination is generally made. The wisdom tooth, like any other tooth, may be the site of infection, but it is my conviction that in certain cases a perfectly healthy but unerupted wisdom tooth may produce grave disturbances in the eyes which must be ascribed either to direct pressure on neighbouring nerves or to some reflex irritation. In the course of special study $\dagger$ of the disorders of eruption of the third molar I have collected 700 cases, half of them from the literature and half of them generously contributed by private practitioners from their case records. Among these I have 18 contributed and 32 literature cases in which there was some ocular symptom.

Among my contributed cases the majority were associated with septic infection and on these I will not lay great stress. They included cases of cyclitis, iridocyclitis and conjunctivitis associated with infected buried wisdom teeth and cured by extraction. The only point that needs emphasis in these cases is that the search for dental sepsis must never be regarded as complete unless it includes radiographic examination of the areas where wisdom teeth may be buried. There are some lamentable cases on record where this investigation was omitted and the eyes were treated for many months without benefit when the whole condition could have been cleared up in a few days had the real cause been discovered. In a case sent me by Mr. Colin Campbell of Toronto the teeth appeared perfect and had been regularly supervised since childhood, but all the same the patient had bilateral iritis with fresh precipitates and stubborn posterior synechiae. The symptoms cleared up quickly when three buried infected third molars were extracted. Brinton ${ }^{1}$ records a case of grave uveitis treated by atropine for three weeks without benefit, but improvement within 24 hours of the extraction of a left upper wisdom tooth, the patient being practically well on the following day.

\footnotetext{
- Copyright of text and figures reserved by autbor.

† The preparation of my Arris and Gale (1934) and Hunterian (1935) Lectures, Royal College of Surgeons of England.
} 
Leiche $^{2}$ reports a male of 42 who was treated by an oculist for three weeks for severe iritis accompanied by neuralgia of the left side of the face and head and the left neck and shoulder. His attack was followed by nervous breakdown, and he spent two months in the country slowly recovering. Six weeks after his return he had a second attack, which lasted a week. He was then referred to a dentist, who discovered an impacted left upper third molar by means of X-rays. He refused extraction until seven months later he had a third attack. The iritis subsided within 12 hours of the removal of the tooth; the neuralgia disappeared within a week; and two years later he had had no recurrence. One of the cases reported by Beck and Oggesen ${ }^{3}$ a girl of 18 years of age, complained of pain in her eyeballs and lacrimation, symptoms which were attributed to eye-strain. She had infected tonsils removed with but slight relief. Later she had slight fever and rapid pulse, suggesting thyroid intoxication, and finally she had been treated for three years for phthisis. All her symptoms subsided and she regained excellent health when three impacted molars were found by $\mathrm{X}$-rays and removed.

Schreiber ${ }^{4}$ records a case of a woman of 27 years of age who had had neuralgic pain in the temple and eye for six years with intermittent blindness. Her right upper first and second molars and second premolar were removed, although they were healthy, without relief. The right lower wisdom was missing from her mouth and was revealed by X-rays impacted in the bone. More extensive films showed an inverted right upper wisdom situated high up in the back wall of the antrum. There is no mention of any infection in this case and all her symptoms cleared up when these teeth had, with some difficulty, been dealt with. A curious condition of the eye due to an impacted wisdom tooth was that reported by Benedict ${ }^{5}$. A woman of 22 years of age had periodic twitching and pulling of the right eyelid for $3 \frac{1}{2}$ years, together with a great deal of headache and face-ache. She was thoroughly examined and, nothing wrong being found, she was referred for a year. When next seen she had had two attacks of severe spasm of the right eyelid. At length a right wisdom tooth was extracted and the patient wrote: "Since I had the impacted tooth removed my eyelid has pulled but little." She had no further attacks and felt as if a weight had been removed from her life. Verrey ${ }^{6}$ has recorded a case of unilateral mydriasis in a female of 34 years of age. She had had toothache for some months with pain radiating to the ear and neck. The eye seemed perfectly normal but its pupil was notably larger than that of the left eye; it returned to normal the day after extraction of a right lower third molar. Stucky ${ }^{7}$ reports two case histories. In the first a female of 20 years of age had iridocyclitis and later typical fulminant 
acute glaucoma. She was so bad that enucleation of the bulb seemed indicated, but, fortunately for her, X-rays were taken and revealed unerupted wisdoms on each side. She improved as soon as they were taken out. The second case was a female aged 28 years who had hypermetropic astigmatism with headache, nervousness and tachycardia. All her troubles were ended when unerupted wisdoms on each side of her mouth were removed.

Mr. A. F. MacCallan sent me notes of a case of diplopia and paresis of the right inferior rectus muscle. Three days after the extraction of her unerupted right upper and right lower third

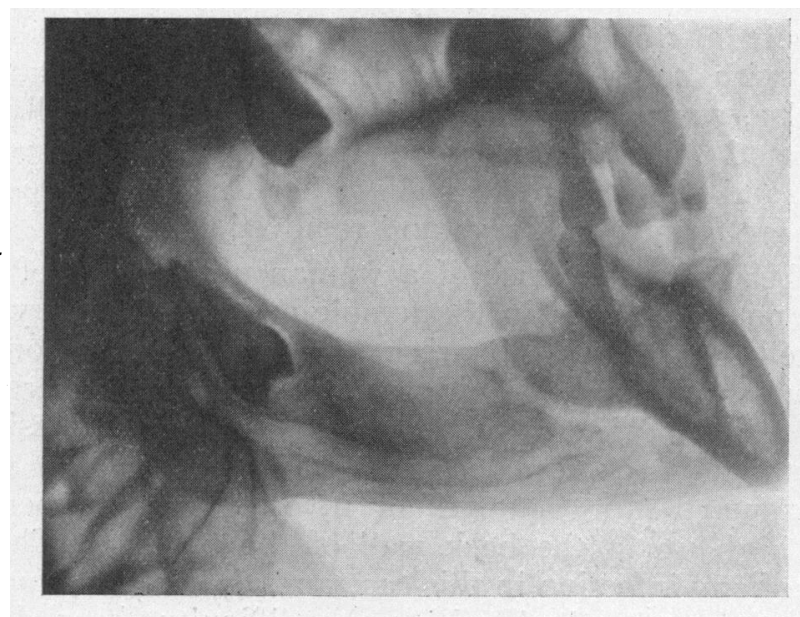

FIG. 1.

molars her condition was normal. Dr. N. Graham Wigram sent me notes of a female aged 26 years, who had ptosis of the right upper eyelid for which no cause could be found despite careful search. Finally, an unerupted right upper wisdom tooth was found and extracted and the symptoms disappeared in a week. Another case was that sent me by Mr. J. W. Watts. The patient was a female aged 60 years, who had proptosis of the left eye with unerupted upper and left lower wisdom teeth (Fig. 1). The eye was normal a fortnight after the extraction of the left upper molar, although septic teeth were present as well and were not at that time treated. She had had the trouble in the eye for years and it had been ascribed to blockage of the lacrimal duct.

A case of Mr. A. A. Clark's, a girl aged 20 years, began to have constant pain in her eyes, making any kind of close work extremely difficult. The pain went on for four years, and then severe attacks of migraine began. Esophoria then developed and 
she underwent two operations for its relief. She visited several oculists and any ophthalmic cause for her trouble was carefully excluded; nevertheless the pain continued. Then pain in the face was added to it, and some considerable stiffness of the jaw. Ultimately X-rays were taken (Fig. 2) and showed a right lower wisdom tooth just emerging from the alveolus and directed a little

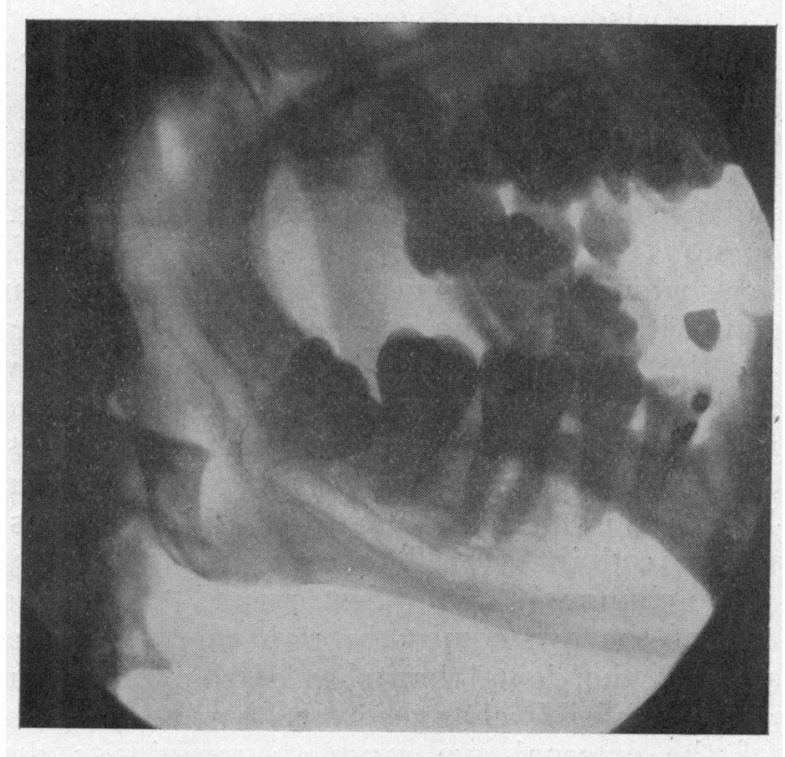

FIG. 2 .

forwards. The tooth in front of it was removed to make room and so relieve the pressure and there was an immediate improvement.

Roller's ${ }^{8}$ case is perhaps the most striking of all my cases in this connection. The patient was a typist aged 35 years who developed very severe iritis of both eyes, particularly the left. The teeth were investigated and X-rays taken, but the specialist decided that they were not responsible and treated her with lotions, hot applications, dark glasses and rest for a fortnight. The pain got worse and she was given a bad prognosis. A second specialist was consulted and he also examined the X-rays and said that the teeth were not to blame. The patient then spent a month in a dark room, after which a third specialist investigated her thoroughly in the search for a toxic focus, including a review of the radiographs. He was unable to find any cause for the ocular disturbance and suggested removal of her perfectly healthy tonsils. Finally, the patient was so extremely depressed, and indeed suicidal, that 
Roller's first care was to encourage her to co-operate with him and not give up hope. When the X-rays were reviewed for the fourth time, the unerupted left lower wisdom tooth was noted. More $\mathrm{X}$-rays were taken and the tooth was removed after a somewhat difficult operation. It was perfectly healthy. Decided improvement was manifest in her eyes three days later, and the bandages were removed in two weeks. In four months she was back at work. The roots of the wisdom tooth were very close to, if not actually touching, the inferior dental nerve, and this case seems to show the possibility that eye conditions may be due to the reflex irritation of pressure upon local nerves in the absence of infection.

$\mathrm{J}$. Jameson Evans ${ }^{9}$ has expressed his difficulty in accepting the ordinary explanation which connects dental and ocular conditions by haematogenous sepsis. He suggests that the disorder of the tooth sets up reflexes which lower the vitality of the eye, and emphasizes the frequency with which one eye only is affected-that of the same side as the offending tooth. This ipsilaterality would be very difficult to explain on the grounds of blood-borne sepsis. In . fact, he says at one point "I am inclined to think that it is possible to get chronic glaucoma set up by the irritation of an unerupted molar." Wilmer ${ }^{10}$ is more cautious still. He classifies diseases which arise from teeth into (1) reflex neuroses, and (2) inflammatory or degenerative changes. In the first group, "the disturbance in the functions of the eye comes through the nervous apparatus from irritation of the dental branches of the trigeminus," e.g., amblyopia without visible changes in the fundus; blepharospasm; paralysis of the external eye muscles; mydriasis; asthenopia, neuralgia, etc. Under the heading of inflammatory or degenerative changes, he includes pulp stones in his list of dental causes, which otherwise are all septic states.

These authors therefore advance towards, without clearly stating, the thesis of this paper, viz., that ocular conditions may be set up in some cases by reflex irritation from the teeth where no sepsis is present.

\section{BIBLIOGRAPHY}

1. Brinton, A. G.-Med. Jl. of South Africa, Vol. II, p. 159, 1915-16.

2. Leiche, T. I.-Internat. Jl. Orthodont., Vol. V. p. 350, 1919. 3. Beck, H. G., and Oggesen, W. L.-Bull. School Med. Univ., Maryland,
Vol. XV, p. 182, 1930-31.

4. Schreiber, W. L.-Dent. Cos., Vol. LXI, p. 111, 1919.

5. Benedict, W. L.-Amer. Jl. of Ophthal., Vol. III, p. 860, 1920.

6. Verrey, L.-Ann. d'Ocul., Vol. CXLVII, p. 189, 1912.

7. Stucky, J. A.-Eye, Ear, Nose and Throat Monthly, Vol. I, p. 10, 1922.

8. Roller, O. P.-Dent. Cos., Vol. LXIV, p. 506, 1922.

9. Evans, J. Jameson.-Lancet, Vol. II, p. 1474, 1933.

10. Wilmer, W. H.-Arch. of Ophthal., Vol. LXI (old series), p. 465, 1930. 